\title{
Anterior Transpetrosal Untuk Lesi pada Fosa Kranialis Media dan Posterior: Review Literatur dan Diseksi Kadaver
}

\author{
Muhammad Zafrullah Arifin, ${ }^{1}$ Agung Budi Sutiono, ${ }^{1,3}$ Ahmad Faried, ${ }^{1,2}$ \\ Takeshi Kawase, ${ }^{3}$ Beny Atmadja Wirjomartani, ${ }^{1}$ Kahdar Wiriadisastra ${ }^{1}$ \\ ${ }^{1}$ Department of Neurosurgery, Universitas Padjadjaran, Hasan Sadikin Hospital, Bandung, Indonesia \\ ${ }^{2}$ Department of Neurosurgery, Gunma University Hospital, Gunma, Japan \\ ${ }^{3}$ Department of Neurosurgery, Keio University Hospital, Tokyo, Japan
}

\begin{abstract}
Abstrak
Reseksi selektif pada bagian anterior piramid os petrosus (segitiga Kawase), dengan terlebih dahulu melakukan kraniotomi pada dinding lateral fosa kranialis media, dapat memberikan lapang pandang bedah yang cukup luas dari parasellar, clivus dan cerebellopontine angle (CPA), tanpa mengorbankan struktur organ pendengaran dalam (internal acoustics organ). Keuntungan utama teknik anterior transpetrosal ini adalah dapat langsung mengakses tumor yang melekat pada klivus melalui rongga kecil yang dibuat pada apeks os petrosus. Pengangkatan tumor dengan perdarahan yang minimal dapat dicapai dengan melakukan koagulasi pada arteri tentorium dan akses langsung ke arah anterior kanalis auditorius internus, juga dapat mengurangi cedera pada nervus fasialis dan vestibulokoklearis. Keuntungan lainnya, yaitu, rendahnya risiko komplikasi perdarahan vena, karena teknik ini tidak mengekspos sinus sigmoid ataupun vena Labbe. [MKB. 2010;42(2):86-91].
\end{abstract}

Kata kunci: Anterior transpetrosal, fosa media dan posterior, diseksi kadaver

\section{Anterior Transpetrosal for Lession in Middle and Posterior Fossa: Literature Review and Cadaver Dissection}

\begin{abstract}
Resection of the anterior part of pyramid through the middle fossa craniotomy will give us a surgical field of the parasellar, clivus and cerebellopontine angle without sacrificing the auditory structure. The advantage of the anterior transpetrosal approach is the direct access to tumors that attached to the clivus via a keyhole created on the petrosus apex. Bloodless tumor removal can be achieved by detachment of the tentorial artery and direct access of the anterior internal auditory canal also can minimize the injury of the cranial nerve facialis and vestibulocochlearis. Another advantage is the low risk of venous damages since this approach is not exposing the sigmoid sinus and the vein of Labbe. [MKB. 2010;42(2):86-91].
\end{abstract}

Key words: Anterior transpetrosal, middle and posterior fossa, cadaver dissection

Korespondensi: Agung Budi Sutiono, MD., PhD, Department of Neurosurgery, Keio University Hospital, 35 Shinanomachi, Shinjuku-Ku, Tokyo 160-8582 Japan, Email: agungbudis@yahoo.com 


\section{Pendahuluan}

Ada empat macam teknik bedah saraf yang telah dikenal untuk mengakses lesi di daerah petroclival atau lesi di daerah prepontin yaitu: suboksipital, translabirin, transpetrosal, serta fosa kranialis media. Teknik transpetrosal dapat memberikan lapang pandang bedah cukup luas untuk tumor di daerah petroklival, tetapi teknik konvensional transpetrosal yang dapat menyebabkan gangguan fungsi pendengaran pasien yang disebabkan oleh reseksi pada daerah tengah os piramid. Reseksi pada bagian posterior os piramid terbatas pada segitiga Trautman (presigmoid approach), dengan memberikan sudut pandang pada klivus bagian bawah saja, akan tetapi akses untuk klivus bagian atas terbatas karena terhalang oleh eminentia arkuata. Komplikasi pada perdarahan vena yang disebabkan oleh terpaparnya sinus sigmoid dan regangan pada vena Labbe merupakan masalah yang cukup signifikan pada teknik presigmoid. Kekurangan tersebut dapat diatasi dengan cara melakukan kraniotomi untuk mendekati fosa kranialis media dan reseksi pada anterior piramid (Gambar 1).

\section{Indikasi}

Indikasi teknik anterior transpetrosal meliputi lesi di daerah klivus bagian atas, prepontin terletak di sebelah medial kanalis auditorius internus (KAI), seperti petroklival meningioma, klival kordoma, trigeminal neurinoma, dan prepontin epidermoid. Teknik ini merupakan indikasi utama untuk tumor yang melekat pada sebelah medial nervus trigeminus atau yang meluas ke arah fosa medialis dan posterior. Indikasi lainnya adalah untuk aneurisma trunkus basilaris yang terletak di antara pituitary floor dan KAI, yang pada gambaran angiogram lateral, aneurisma dapat terlihat pada daerah trunkus basilaris atas, arteri anteroinferior serebelaris (AICA), serta vertebrobasilar junction. Teknik ini sangat berguna pada aneurisma di batang otak karena perforasi arteri di sekitar aneurisma dapat terlihat. Pada petroklival yang meluas ke lateral menuju KAI perlu dilakukan labirintektomi secara partial. Tindakan oateotomi zigomatik dapat dikombinasikan dengan teknik anterior transpetrosal (zygomatic trans petrosal approach) sebagai indikasi tumor yang meluas ke posterior prosesus klinoid. Kelemahan dari teknik ini adalah sulitnya mendekati di daerah sepertiga bagian bawah klivus dan vertebrobasilar junction, sehingga kombinasi dengan transcondylar atau presigmoid diperlukan untuk melihat sepertiga distal bagian klivus.

\section{Persiapan Operasi}

Sebelum operasi, diperlukan drainase spinal untuk mengurangi tekanan pada lobus temporalis. Kasus tumor yang cukup besar, pada trigonum ventrikel lateral dapat dilakukan puncture likuor sebagai drainase likuor serebrospinal. Pasien dalam posisi supine, diletakkan bantal di bawah bahu membentuk sudut $20^{\circ}$. Posisi kepala sedikit diputar ke arah lateral dan sumbu aksis fleksi ke bawah. Posisi kepala ke lateral ini penting, untuk

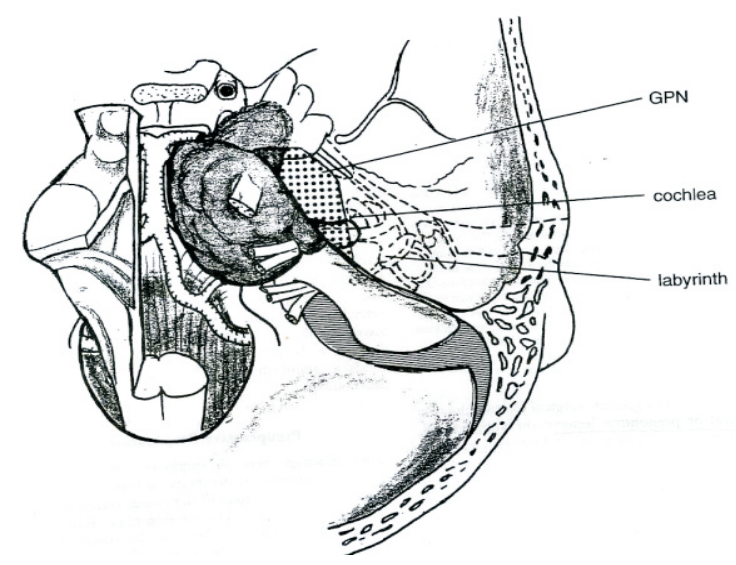

Gambar 1 Reseksi pada Piramid, Daerah Bintik-bintik Adalah Reseksi Untuk Memasuki Daerah Anterior Piramid.

Sumber: Kawase dkk. ${ }^{1}$ 
identifikasi anatomi tulang temporalis. Earphone dan elektroda dipasang apabila memiliki alat monitor auditory brainstem response (ABR). Telinga dilipat-dijahit sehingga menutupi meatus akustikus eksternus dan earphone. Intra operative facial nerve monitoring dipasang jika diperlukan. Pada kasus aneurisma di trunkus basilaris, intravaskular balon kateter dapat dimasukkan pada kedua sisi arteri vertebralis jika terjadi ruptur aneurisma.

\section{Teknik Operasi}

\section{Insisi dan kraniotomi}

Buat insisi berbentuk U di atas telinga (Gambar 2), insisi lurus di bagian anterior, bertujuan untuk menghindari cederanya nervus fasialis. Batas atas yang dibuat sedemikian rupa mengikuti garis sfenotemporalis agar fasia muskulus temporalis dapat digunakan sebagai flap untuk menutup duramater setelah operasi selesai. Jika teknik ini dikombinasikan dengan teknik pterional atau dengan melakukan osteotomi pada tulang zigoma (zygomatic transpetrosal approach), maka insisi berbentuk question mark. Selanjutnya otot fasia temporalis dipisahkan dengan meninggalkan pedicle di bagian inferior, lalu otot temporalis ditarik ke anterior. Untuk melakukan kraniotomi 3 buah burr hole dilakukan di bawah sutura skuamosa, superior meatus akustikus eksternus, dan arkus zigomatikum. Kraniotomi diarahkan ke bawah bagian tengah mendekati mandibular joint dan meatus auditorius eksternus, lalu dilakukan pada batas luar sutura skuamosa sehingga sinus sigmoid tidak perlu dibuka. Selanjutnya di bagian anteroinferior kraniotomi dilakukan drilling agar foramen spinosum terlihat.

\section{Mengekspos dan mereseksi anterior os piramid}

Piramid os petrosus akan terlihat dari luar epidural sehingga petrous rim juga tampak dengan jelas. Sebelumnya drainase lkuor serebropinal perlu dilakukan untuk mencegah tekanan pada lobus temporalis setelah operasi selesai. Foramen spinosum yang terletak di bagian dasar fosa medialis akan tampak dan arteri meningeal media dikoagulasi lalu dipotong. Perdarahan vena di sekitar foramen ovale dihentikan menggunakan oxycellulose. Nervus petrosus superior mayor dan minor dapat dipastikan melekat pada duramater dekat hiatus nervus petrosus os piramid di sebelah posterior foramen ovale, di sepanjang eminantia arkuata. Lakukan diseksi secara hati-hati pada lapisan duramater yang melekat di sebelah lateral (Gambar 3). Nervus petrosus superior mayor greater superior petrosal nerve (GSPN) jangan ditarik terlalu kuat karena nervus fasialis di piramid dapat terganggu.

Retraktor sugita digunakan untuk meretraksi duramater agar apeks piramid tulang petrosus dapat terlihat. Dengan melepaskan periosteum pada nervus mandibularis dapat mengurangi regangan pada duramater. Mikroskop diarahkan ke bagian anterior piramid. Pada permukaan piramid akan tampak dua penanda, yaitu eminentia arkuata dan trigeminal impression. KAI berada tepat di anterior eminentia arkuata, dengan kedalaman kira-kira $7 \mathrm{~mm}$ dari permukaan tulang. Ganglion genikulatum terletak di perpanjangan garis GSPN, pada persilangan antara meatus

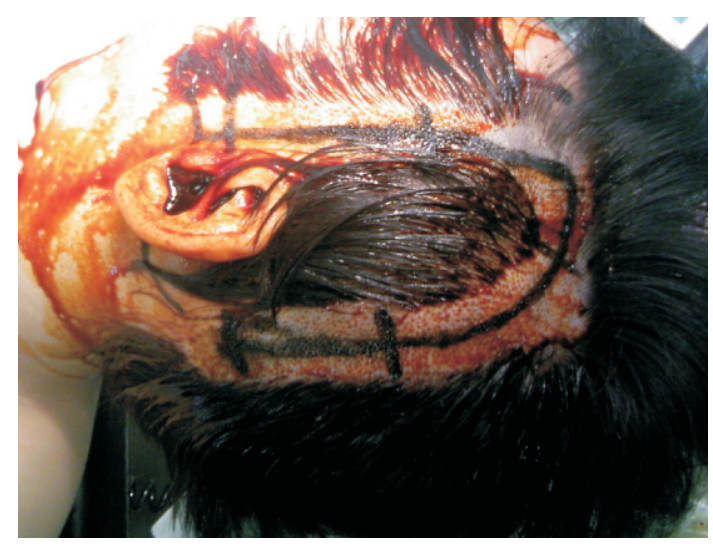

Gambar 2 Insisi Berbentuk U Untuk Teknik Anterior Transpetrosal Sumber: Department of Neurosurgery, Keio University Hospital, Japan. 

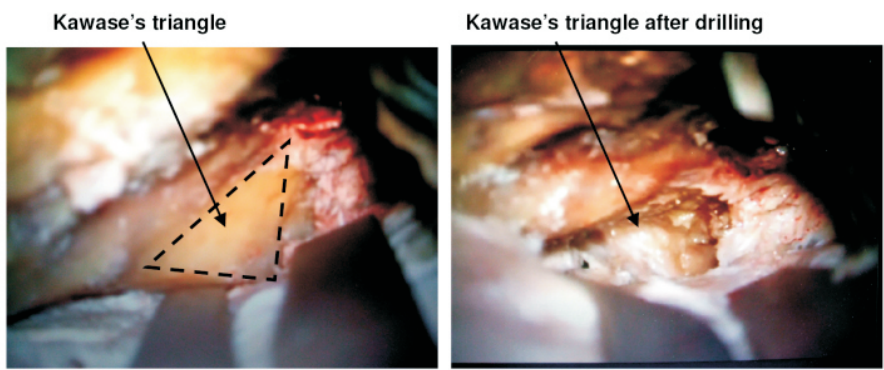

Gambar 3 Tempat Dilakukan Diseksi Duramater dan Daerah Aman Drilling

Sumber: Shimamoto dkk. ${ }^{7}$

auditorius interna dan eksterna. Koklea terletak di antara kedua sudut garis tersebut, dan dari arah operator, arteri karotis dan tuba eustachius terletak di sebelah lateral GSPN. Batas maksimal untuk reseksi tulang agar struktur pendengaran tidak terganggu terletak di medial GSPN, anterior eminentia arkuata dan superior kanalis auditorius internus. Tahap awal untuk menghindari cedera pada superiorinferior sinus petrosus, lapisan tipis piramid yang menghadap fosa posterior dapat dipertahankan dengan cara enukleasi piramid bagian tengah. Reseksi lebih dalam ke arah posterior harus dilakukan hati-hati menggunakan diamond burr $2 \mathrm{~mm}$ sehingga tidak menembus duramater pada portal KAI. Reseksi pada tulang tempat masuknya nervus trigeminus penting dilakukan untuk memudahkan mobilisasi nervus trigeminus ke arah inferior. Reseksi tulang harus dilakukan hingga tidak tersisa jaringan tulang yang menempel pada rim. Dengan demikian nervus V dan VI dapat terlihat setelah dilakukan reseksi.

\section{Insisi dura}

Buat insisi apertura pada duramater di daerah fosa posterior dengan microknife, maka vena petrosus dan AICA akan tampak di sisterna CPA. Pada tumor yang terletak pada petroklival, sisterna umumnya bersatu dengan tumor. Selanjutnya basal dura pada fosa medialis diinsisi sepanjang 2 $\mathrm{cm}$ tegak lurus sinus petrosus superior, lalu insisi sejajar dengan sinus sehingga berbentuk seperti huruf $\mathrm{T}$, lalu retraktor diletakan pada lobus temporalis. Sinus petrosus superior diligasi di dua tempat, kemudian dipotong. Vena petrosus harus masuk ke bagian posterior sehingga peredaran darah vena tetap bisa dipertahankan. Tahap ini diikuti dengan insisi pada tentorium (Gambar 4).

Pada meningioma petroklival, insisi dura dilakukan sedekat mungkin dengan bagian dari posterior tumor yang melekat pada sisi tulang. Perhatikan nervus IV yang terletak pada tepi tentorium, jangan sampai terpotong. Pada kedua sisi tepi tentorium disisihkan dengan jahitan, kemudian nervus $\mathrm{V}$ tampak pada bagian tengah lapang pandang bedah, terfiksasi pada Meckel's cave. Dura pada tentorium diinsisi sepanjang $1 \mathrm{~cm}$ untuk memudahkan mobilisasi nervus $\mathrm{V}$, sehingga nervus VI dan trunkus basilaris dapat terlihat.

\section{Studi pada Beberapa Kasus}

\section{Aneurisma trunkus basilaris}

Hubungan antara nervus kranialis dan aneurisma bergantung pada letak aneurisma tersebut. Aneurisma trunkus basilaris atas terletak di antara nervus IV dan V, sehingga pada posisi ini, nervus
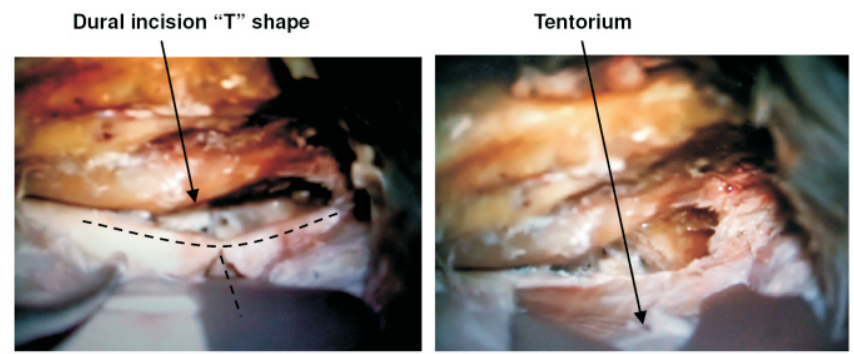

Gambar 4 Setelah Dilakukan Insisi pada Tentorium Sumber: Kawase dkk. ${ }^{6}$ 
$\mathrm{V}$ dapat digeser ke arah inferior. Aneurisma pada bifurcation AICA biasanya terletak antara nervus VI dan VII sehingga nervus $\mathrm{V}$ dapat digeser ke arah superior. Aneurisma pada vertebrobasilar junction akan tampak pada posisi terendah dari reseksi tulang antara nervus VI dan VII (Gambar $5)$.

Batang otak tidak boleh diretraksi ke anterior sedemikian rupa agar aneurisma terlihat. Pada aneurisma di posterior, pons dapat dilindungi dan dikelilingi dengan perforator seperti tampak pada aneurisma di bifurkatio basilar. Pertahankan arteri perforator pada waktu dilakukan klipping.

\section{Tumor petroklival}

Pada meningioma petroklival, lokasi nervus kranialis dapat berbeda-beda pada tiap kasus dan dapat dikelompokkan menjadi: terletak di atas klivus, terletak pada sinus kavernosus, terletak pada tentorium, dan terletak pada apeks petrosus.

Tumor pada klivus bagian atas dan sinus kavernosus menyebabkan posisi pada nervus trigeminus bergeser ke arah lateral (Gambar 6), dan sebaliknya nervus trigeminus akan bergeser ke arah medial jika tumor terletak pada tentorium dan apeks petrosus. Meningioma yang berada pada petroklival biasanya perlekatannya meluas ke tentorium pada $50 \%$ kasus dan tumor menginvasi Meckel's cave, sehingga tentorium harus dipotong sepanjang batas posterior dari perlekatan tumor. Jika tumor meluas ke fosa medialis, tumor harus diangkat sebelum tentorium diinsisi. Hati-hati pada saat melakukan insisi tadi jangan sampai mencederai nervus trigeminus yang terdorong ke bawah sinus petrosus superior. Pada banyak kasus, nervus III dan IV bergeser ke arah superior. Pengambilan tumor dimulai dari Meckel's cave untuk memudahkan mobilisasi nervus $\mathrm{V}$, akan tetapi perlu diingat bahwa nervus $\mathrm{V}$ bercabang menjadi tiga di dekat cave dan tertutup oleh tumor. Setelah menggeser nervus V ke inferior dan nervus IV ke superior dengan cara melepaskan tentorium yang kemudian dilakukan diseksi tumor dari klival duramater.

Feeding arteri dikoagulasi (arteri tentorium) lalu dipotong di antara nervus IV dan V sehingga perdarahan berkurang pada saat melakukan dekompresi interna pada tumor. Lapang pandang bedah harus bersih untuk mengawasi superior cerbellar artery (SCA) yang terletak dekat tumor. AICA dan arteri basilaris akan terlibat jika tumor tersebut sangat besar. Nervus abdusens biasanya akan bergeser ke arah medial dan terletak pada medioinferior dari nervus $\mathrm{V}$ setelah pengangkatan tumor. Setelah dilakukan dekompresi tumor maka mulai dari nervus III-VII menjadi tidak teregang lagi. Bagian dari nervus IV dan $\mathrm{V}$ yang menembus dura biasanya terinvasi tumor. Apabila periedema tumor tampak dekat batang otak pada gambaran MRI T2-weighted, maka bagian tumor yang menempel pada batang otak harus ditinggalkan karena permukaan araknoid yang terletak di antara tumor dan batang otak tidak dapat diangkat. Trigeminal neurinoma, kordoma, dan epidermoid bersifat tidak terlalu melekat pada nervus kranialis dan batang otak jika dibanding meningioma. Bagian posterior sinus kavernosus dapat dibuka jika diperlukan, dengan melakukan insisi pada dinding medial Meckel's cave. Segitiga Parkinson dapat diperluas dengan menggeser nervus $\mathrm{V}$ ke inferior dan nervus IV ke superior bersama-sama dengan tentorium. Perdarahan dirawat dengan

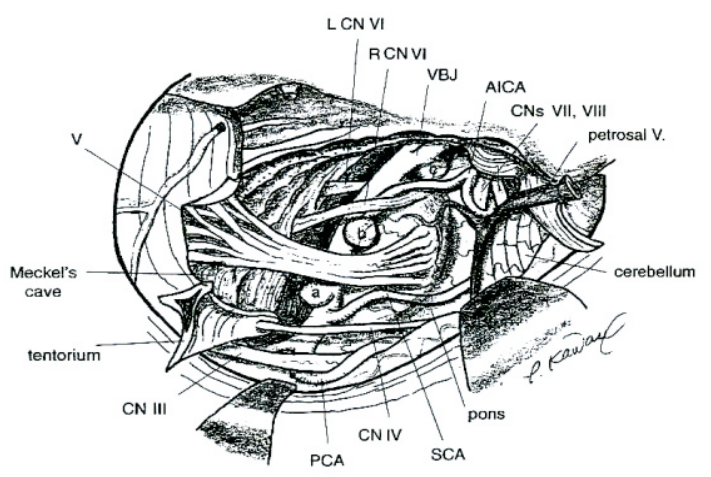

Gambar 5 Letak Aneurisma dan Nervus Kranialis: a) Aneurisma Basilar Trunk Atas, b) Aneurisma Bifurcation AICA, dan c) Aneurisma Vertebrobasilar Junction.

Sumber: Kawase $\mathrm{dkk}^{3}$ 


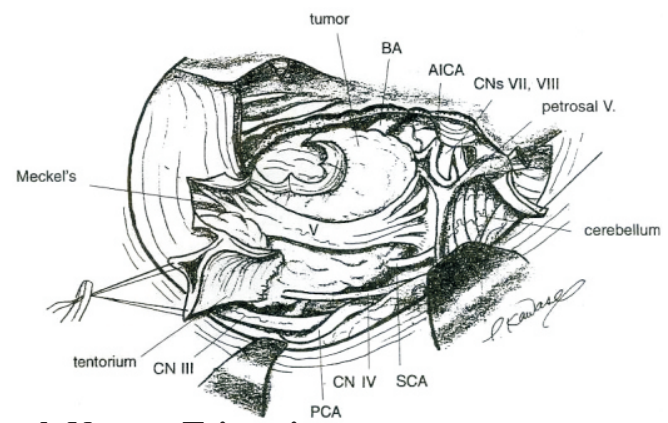

Gambar 6 Meningioma Melintang di Tengah Nervus Trigeminus Sumber: Kawase $\mathrm{dkk}^{3}$

memberikan oxycel pada sinus kavernosus dan inferior sinus petrosus. Carotid loop (pada lengkung $\mathrm{C} 4$ dan $\mathrm{C} 5$ ) dan nervus VI yang melewati Dorello's canal dapat terlihat dengan jelas. Meningioma pada sinus kavernosus lebih bersifat fibrosis dan menempel pada struktur di sekitarnya, sehingga identifikasi arteri karotis menggunakan Doppler mikrosonografi dapat membantu untuk mengetahui letak arteri karotis interna.

\section{Menutup luka operasi}

Apeks petrosus yang telah di drill ditutup dengan flap fasia temporalis dan diberi fibrin glue. Rongga mastoid yang terpapar ditutup dengan fasia flap, sedangkan rongga apeks petrosus yang luas dapat ditutup dengan jaringan lemak yang diambil dari lemak di subkutaneus abdomen. Defek dura ditutup dan dijahit dengan flap fasia dan diberi fibrin glue untuk mencegah akumulasi LCS di bawah scalp kemudian kraniotomi ditutup.

\section{Daftar Pustaka}

1. Kawase T, Bertalanffy H, Otani M, Shiobara R, Toya S. Surgical approach for vertebro-basilar trunk aneurysm located in the midline. Acta Neurochir. 1996;138:402-10.

2. Kawase T, Shiobara R, Ohira T, Toya S. Developmental patterns and symptoms of petroclival meningiomas. Neurol Med Chir. 1996;36:1-6.

3. Kawase T, Toya S, Shiobara R, Mine T. Transpetrosal approach for the aneurysm of the lower basilar artery. J Neurosurgery. 1985;63:857-67.

4. Kawase T, Toya S. Anterior transpetrosal approach for basilar trunk aneurysm: further experience. Dalam: Pasqualin A, Da Pian R, penyunting. New trends in management of cerebrovascular malformations. Austria: Sprienger-verlag; 1994. hlm. 255-60.

5. Kawase T, Shiobara R, Toya S. Anterior transpetrosal transtentorial approach for sphenopetroclival meningiomas: surgical method and results in 10 patients. Neurosurgery. 1991;28:869-76.

6. Kawase T, Shiobara R, Toya S. Middle fossa transpetrosal transtentorial approaches for petroclival meningiomas: Selective pyramid resection and radicality. Acta Neurochir. 1994;129:113-20.

7. Shimamoto Y, Kawase T, Sasaki H, Shiobara R, Yamada F. Anterior transpetrosal approach to the prepontine epidermoids. Skull Base Surgery. 1999;9(1):75-80.

8. Steiger HJ, Hanggi D, Stummer W, Winkler PA. Customs tailored transdural anterior transpetrosal approach to ventral pons and retroclival regions. J Neurosurg. 2006;104:38-46.

9. Katayama M, Kawase T, Sato S, Kojima A, Yoshida K. Abnormal course of the oculomotor nerve on the clivus combined with a petroclival meningioma: case report. Skull Base. 2002;12(3): $141-4$.

10. Sato S, Oizumi T, Sato M, Nishizawa M, Ishikawa $\mathrm{M}$, Inamasu $\mathrm{G}$, dkk. Enlarge entry space for the transpetrosal approach. Skull Base. 2000;10(2): 59-63. 